\title{
FRAMING USER RESPONSES TO THE INTRODUCTION OF NEW INFORMATION TECHNOLOGY IN THE CONTEXT OF NEGATIVE CAPABILITY
}

\author{
Judith Decou, University of the West of England, jdecou@uwindsor.ca \\ Diana Kao, University of Windsor, kao@uwindsor.ca
}

\begin{abstract}
Resistance and acceptance responses to the introduction of new information technology (IT) are frequently considered separately and explored with the precept that users have an option in accepting new IT. By expanding on the concept of negative capability, a new model for user responses is proposed that is applicable for optional or mandatory situations.
\end{abstract}

Keywords: IT Adoption, User Acceptance, Resistance to Change

\section{INTRODUCTION}

User resistance to the introduction of new information technology into the organization was identified as a concern in early MIS research $[15,18]$. Yet, as IT has become an integral part of the business landscape, user resistance to new installations continues to be observed [15]. However, none of the attempts to model resistance, to date, have allowed incorporation of all of the potential elements that contribute to the phenomenon.

IT models of resistance, as well as models of adoption, tend to view IT adoption as optional. As technology advances, organisations will continue to increase their reliance on IT. Consequently, there is a need to look at user responses with the goal of understanding how individuals come to accept the adoption of new IT that they initially resist. In addition, it is important to examine this acceptance in circumstances where the adoption of the IT is mandatory for all potential users in the organization.

Although some of the extant models of resistance may suggest certain psychological factors contribute to resistance, none explain the process of working through the resistance to acceptance. This paper proposes a framework to better understand resistance and acceptance, and the process of moving from resistance to acceptance through the lens of negative capability.

\section{DEFINING NEGATIVE CAPABILITY}

...several things dovetailed in my mind, \& at once it struck me, what quality went to form a Man of Achievement especially in Literature \& which Shakespeare possessed so enormously - I mean Negative Capability, that is when a man is capable of being in uncertainties, Mysteries, doubts, without any irritable reaching after fact \& reason [14].

John Keats first identified the concept of negative capability in a letter to his brothers in 1817. Since Keats's time, the concept has been expanded and interpreted to apply to a number of applications and disciplines. In order to further unpack the concept, the etymology of the term "negative capability" is discussed and the application of the concept of negative capability is examined to determine the potential relevance to the study of information technology.

Perhaps the most important issue to examine is the seemingly-contradictory nature of the term "negative capability". It would seem to suggest "lacking in ability". However, if one thinks of "negative" in terms of a negative pole of a magnet or negative electricity, one might better grasp its meaning in this context. It does not suggest "not capable" but rather "capability in negative situations".

The etymology of the words "negative" and "capability" provide further insight into the meaning that Keats intended for the phrase. The word "negative" may be defined as "opposite to something regarded as positive [11]. Its origin is in the Latin word negativus from negatus, the past participle of negare meaning "to deny". An obsolete 
meaning of "capable" is capacious - being able to contain or hold much; roomy; spacious [11]. The origin of capacious is the Latin capax from capere, meaning to take, hold and contain [11]. In the context attributed to Keats, we might think of capability as the ability to contain. In applying these interpretations to "negative capability" it might suggest an individual who is psychologically able to deal with negative or unfamiliar circumstances.

Application of negative capability in several disciplines is summarized briefly to better understand its potential application to MIS.

\section{CURRENT UNDERSTANDING OF NEGATIVE CAPABILITY IN VARIOUS DISCIPLINES}

Negative capability has been discussed in a number of disciplines, including literary studies, philosophy and psychotherapy. In literary studies, several insights into negative capability emerged (see Wigod [11], Bate [2]). Wigod [11] suggested that Keats would consider the thoughts of Man, "maintaining an open mind, a capacity for change, and an aversion to forming comfortable - but in reality unsatisfying - resolutions and philosophies" [11]. This interpretation is important in that it broadens the relevancy of "negative capability" beyond its application to literary pursuits to encompass any situation encountered. Within the discipline of philosophy, "negative capability" has been associated with Zen philosophy and the concept of satori [6]. Bion applied negative capability as a concept that relates to the practice of psychotherapy, reflected in the therapist's ability to observe and appreciate observation without 'irritable reaching after fact and reason'” [7].

Literature in the fields of psychology and management studies contributed to the development of the concept in the current research and is presented here in more detail. In the field of psychology, negative capability has been described as "the experience of being drawn into fully experiencing anxious feelings without attempting to flee" [22]. In relating it to the experience of anxiety, Stuart [22] described anxiety experiences that both precluded and indicated negative capability. The conditions were subdivided into three consecutive steps; the first two make negative capability possible while the third demonstrates its presence. The first step is typified by increasing anxiety and a perceived threat to one's wellbeing. Familiar coping strategies are adopted, but fail to alleviate the situation. The second step exhibits heightened physical and psychological symptoms as coping strategies prove ineffective. The third step begins when the struggle against the experience of anxiety and the passive struggle to change the situation fail. One adopts a present, rather than past or future, orientation and begins to understand the situation in a different way, and objective solutions emerge [22].

Negative capability has also been applied to management studies, e.g., Bennis [4, 5] and French [9, 10]. French [10] defined it as "the capacity to experience emotion, one's own and others', but also to "contain" it until it has "informed" us and hence reformed our understanding". It is considered to be a "gift", a character trait that some people possess in greater abundance than do others [10]. It is also suggested that negative capabilities may be developed [9]. It may be invoked as a means to deal with uncertain situations (the capacity to sustain reflective inaction [original emphasis]) [21]. The lack of negative capabilities results in "dispersal behaviors". These behaviors, adopted from Needleman [20], include dispersal as activity, explanations or physical action. As described by French [10], dispersal into activity may be demonstrated by initiating alternative courses of action, rather than dealing with the issue at hand. Dispersal into explanations may be demonstrated by individuals explaining an organization's history to account for current conditions, while dispersal into emotion may be demonstrated by physical reactions to stress, such as back pain, or tears.

By applying the understanding of negative capability in other disciplines, a model of user responses to the introduction of new IT may be developed.

\section{APPLYING NEGATIVE CAPABILITY TO USER RESPONSES TO NEW IT}

While adoption of new IT was formerly an option for many potential users, the use of technology is becoming mandatory. Consequently, it is often not a question of whether or not an individual will accept new technology, but rather a question of how to help the user become comfortable with its use and reduce resistance. 
Resistance has been recognized as arising from causes such as fear of technology [3], technostress [8], loss of status, change in interpersonal relationships, economic insecurity, loss of power [13,15,18], power issues [18], alienation [1], reduced job autonomy [24,19], differing styles between users and designers [12] and increased job complexity. It may be demonstrated by behaviors such as minimizing the implementer's access to necessary information [15], sabotage or passive resistance.

Markus [18] suggests, "better theories of resistance will lead to better implementation strategies and, hopefully, to better outcomes for the organizations in which the computer applications are installed". Therefore, further consideration of resistance is warranted.

It is suggested that a negative capability model of user responses to new information technology will be useful in examining user responses to the introduction of new information technology in organizations, including resistance responses. The model illustrated in Figure 1 situates the current understanding of negative capability in other disciplines into the context of the introduction of new IT in the organization.

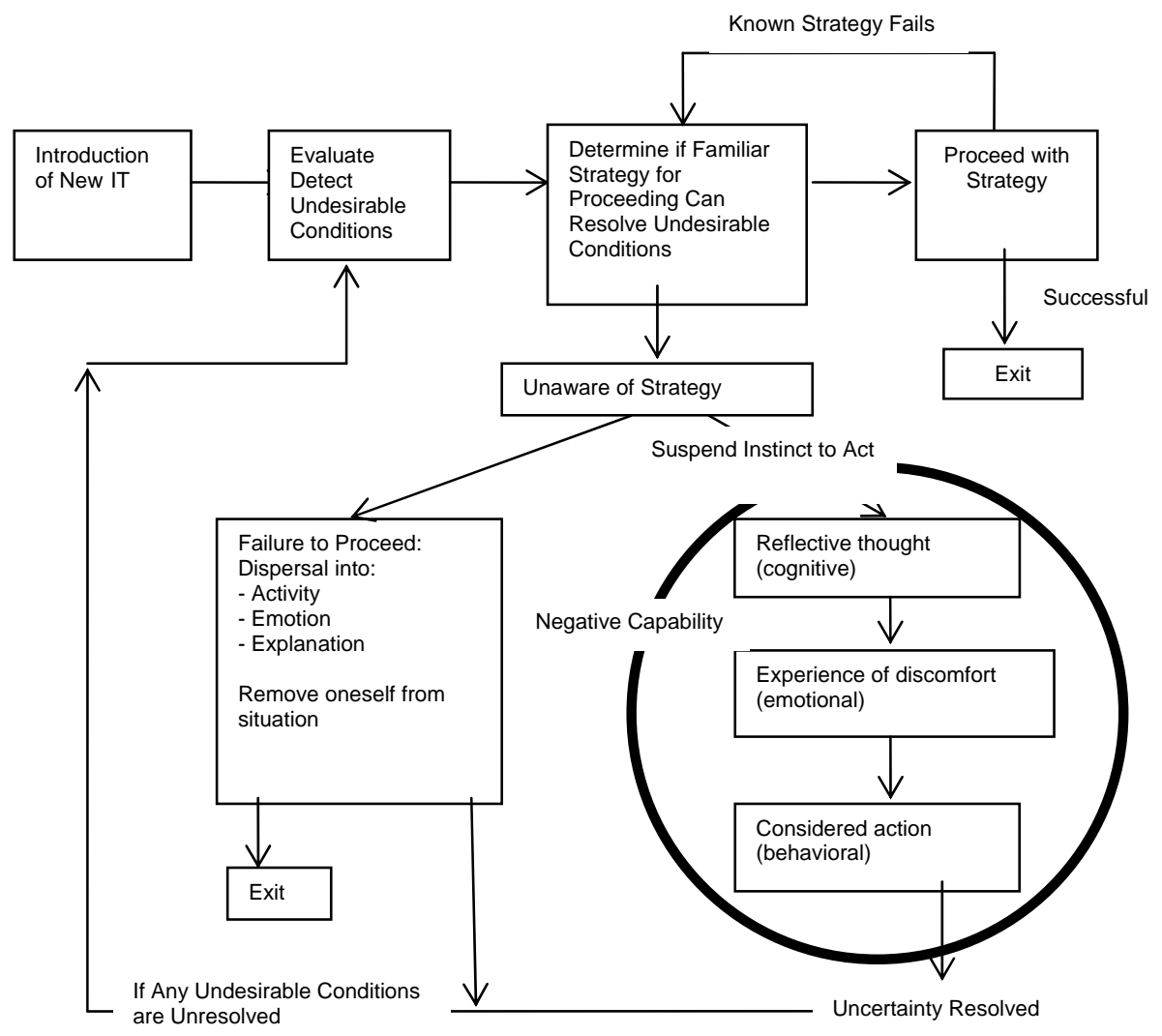

Figure 1: Negative Capability and the Introduction of New Information Technology

In order to better understand the potential usefulness of the model, consider the introduction of a new IT into the organization. Individuals evaluate the change and form an opinion about the new IT.

Depending on personal differences and past experiences, the individual might feel optimistic about the new IT, or may feel uncomfortable with it. If the individual feels comfortable with the change, he/she will willingly adopt of the new IT. If the strategy to adopt the new IT is successful, this individual exits the model. However, if the individual is unable to find a strategy to deal with the new IT, two options exist: to resist or call upon one's negative capability. If negative capability is employed, the individual will work through the discomfort experienced in the change to find a way to co-exist with the new IT. Otherwise, resistance will emerge, the extreme being refusal to 
use the new IT. In the context of mandatory adoption, refusal may be resignation from the job while other dispersal behaviors will end with the individual re-entering the loop, possibly when another employee provides an acceptable strategy to deal with the change.

\section{CONCLUSIONS}

Because the negative capability model was developed from extant literature on negative capability, it will need to be refined and further clarified. Better understanding of the processes involved will follow from a more in-depth evaluation of the IT, psychology and organizational behavior literature, and after the completion of field research. This model may be a useful framework for further research into user responses to new IT. While it may account for situations in which users refuse to adopt the proposed IT change, it also allows for situations in which the IT change is mandatory. The question arises: If a strong sense of negative capability improves a person's ability to deal with the implementation of new IT, will assisting employees to develop their own negative capability reduce resistance behaviors? Field research is necessary to further develop the model in the context of the introduction of new IT. Interviews are currently being conducted with people experiencing the introduction of new IT to their work.

\section{REFERENCES}

1. Abdul-Gader, A. H. and Kozar, K. A. (1995). The impact of computer alienation on information technology decisions: An exploratory cross-national analysis. MIS Quarterly, 19(4), 535-559.

2. Bate, W. J. (1963). John Keats. Cambridge: The Belknap Press of Harvard University Press.

3. Benamati, J. S., Lederer, A. L. and Singh, M. (1997). Changing information technology and information technology management. Information \& Management, 31(5), 275-288.

4. Bennis, W. (1989). On becoming a leader. Reading, Mass: Addison-Wesley Publishing Company, Inc.

5. Bennis, W. (2001). Leading in unnerving times, Sloan Management Review. 42(2), 97-103.

6. Benton, R. P. (1966). Keats and Zen. Philosophy East and West, 16(1/2), 33-47.

7. Bion, W. R. (1970). Attention and interpretation. New York: Basic Books, Inc.

8. Brillhart, P. L. (2004). Technostress in the workplace: Managing stress in the electronic workplace. Journal of American Academy of Business, 5(1/2), 302-307.

9. French, R. (2000). 'Negative Capability', 'Dispersal' and the Containment of Emotion. 17th Annual Meeting of the International Society for the Psychoanalytic Study of Organizations, London UK. Available: http:/library.ispso.org /library/\%E2\%80\%98negative-capability \%E2\%80\%99-\%E2\%80\%98dispersal \%E2\%80\%99-and-containment-emotion.

10. French, R. (2001). "Negative capability": Managing the confusing uncertainties of change, Journal of Organizational Change Management. 14(5), 480-492.

11. Guralnik, D. B. (Ed.) (1970). Webster's new world dictionary. Toronto: Nelson, Foster \& Scott Ltd.

12. Janson, M. A., Woo, C. C. \& Smith, L. D. (1993). Information systems development and communicative action theory. Information \& Management, 25(2), 59-72.

13. Jiang, J. J., Muhanna, W. A. \& Klein, G. (2000). User resistance and strategies for promoting acceptance across system type. Information \& Management, 37(1), 25-36.

14. Keats, J. (1970). Letters of John Keats. Oxford Paperbacks, Oxford, England.

15. Keen, P. G. W. (1981). Information systems and organizational change. Communications of the ACM, 24(1), 24-33.

16. Lapointe, L. \& Rivard, S. (2005). A multilevel model of resistance to information technology implementation. MIS Quarterly, 29(3), 461-491.

17. Marakas, G. M. \& Hornik, S. (1996). Passive resistance misuse: overt support and overt recalcitrance in IS implementation, European Journal of Information Systems. 5(3), 208-219.

18. Markus, M. L. (1983). Power, politics, and MIS implementation. Communications of the ACM, 26(6), 430-444. 
19. Munkvold, B. (1999). Challenges of IT implementation for supporting collaboration in distributed organizations. European Journal of Information Systems, 8(4), 260-272.

20. Needleman, J. (1982). Lost Christianity: A journey of rediscovery to the center of Christian experience. New York, NY: Bantam.

21. Simpson, P., French, R. and Harvey, C. E. (2002). Leadership and negative capability. Human Relations, 55(10), 1209-1226.

22. Stuart, K. (1996). Negative capability: A phenomenological investigation of creatively dwelling with experiences of anxiety. Saybrook Instititute.

23. Wigod, J. D. (1952). Negative capability and wise passiveness. PMLA, 67(4), 383-390.

24. Zuboff, S. (1982). New worlds of computer-mediated work. Harvard Business Review, 60(5), 142-152. 